\title{
EVOLUCIÓN DE UN PERSONAJE MÍTICO: CASANDRA, DE LOS TEXTOS CLÁSICOS A LA NOVELA HISTÓRICA CONTEMPORÁNEA ${ }^{1}$
}

Pilar Hualde Pascual

Universidad Autónoma de Madrid

\section{RESUMEN}

La figura de la profetisa Casandra, documentada en la literatura griega desde los textos homéricos, aparece bien representada en la obra de Esquilo y Eurípides, donde adquiere los rasgos que definirán al personaje en la tradición posterior. La novela histórica contemporánea ha retomado en repetidas ocasiones la figura de la profetisa troyana para, partiendo de las fuentes clásicas, hacer una lectura actual del personaje.

' Este trabajo se adscribe al Proyecto de Investigación 06/0057/98 de la Consejería de Educación y Cultura de la Comunidad de Madrid. Parte del material aquí expuesto se utilizo en una comunicación al $2 .^{\circ}$ Coloquio de Estudiantes de Filología Clásica, celebrado en Valdepeñas en julio de 1990. Asimismo, parte de este trabajo se expuso como conferencia con el título de «Personajes femeninos: de los textos grecolatinos a la literatura contemporánea», en el Curso El Legado Clásico III (Dpto. de Filología Clásica - Instituto de Ciencias de la Educación. U.A.M.) el 25 de enero de 1998. 


\section{INTRODUCCIÓN}

Que los mitos griegos siguen haciendo oír su voz en la sociedad actual es algo evidente: en la pintura, en las representaciones teatrales, en la literatura, sea novela, poesía o ensayo, es muy frecuente encontrarnos con los personajes míticos acuñados hace milenios en los textos del viejo Homero. Evidentemente, estas figuras míticas, ya en la propia Antigüedad, adquieren con el transcurso del tiempo nuevos rasgos en función del uso que se hace del personaje por parte del autor clásico y siguen asumiendo nuevas características en su utilización por parte de los autores contemporáneos. En estas líneas nos vamos a ocupar de un personaje tradicionalmente marginal pero singularmente atractivo, el de Casandra, la hija de Príamo, que aparece de manera puntual en los poemas homéricos, adquiere cierto protagonismo en los trágicos griegos Esquilo y Eurípides (en Agamenón y Las Troyanas respectivamente), se asocia a partir de la Edad Media y el Renacimiento a la literatura que versa sobre la guerra de Troya (así en Boccaccio, Chaucer o Shakespeare), llega hasta la novela histórica contemporánea en Kassandra de la escritora alemana Krista Wolf, quien inaugura una visión «feminista» del personaje y, más recientemente, se retoma en Cassandra. Princess of Troy de la novelista Hilary Bailey.

2. Primeras fuentes. Homero. El ciclo épico. La lírica

\subsection{Homero}

El nacimiento del mito de Casandra en la literatura griega ${ }^{2}$ hay que buscarlo ya en los orígenes de la épica. Es Homero quien por primera vez en la literatura menciona al personaje, si bien éste no presenta aún los rasgos que en la tradición posterior van a caracterizar la figura de Casandra: el don de profecía y la vinculación al dios Apolo. Por el contrario, en los textos homéricos se destacan las características que presentamos a continuación:

2 Para las fuentes del mito cf. Grimal, P. (1984, 2," reimpr.), Diccionario de Mitología Grie. ga y Romana, Barcelona, Paidós, 1984, s.v. Casandra, pp. 89-90; Ruiz DE ElviRA, A. (1982, 2.a ed.), Mitología Clásica, Madrid, Gredos, 1982 (2." edición), pp. 399-400. y, de manera exhaustiva, en ROSCHER, W.H. (1884-1924), Ausfürliches Lexicon der Griechischen und Römischen Mytologie. Leipzig. Teubner. Estudios concretos sobre el mito de Casandra son los de DAVREux, J. (1942), La légende de la prophétesse Cassandre, Lieja; Kakridis, J. Th. (1928), Kassandra, Anz. Akad.Wiss.Wien, y, más recientemente, MASON, P.G. (1959), «Kassandra», J.H.S. 79, pp. 80-93. 
a) La belleza: Casandra destaca por su belleza entre las hijas de Príamo, algo que ignorarán posteriormente los trágicos griegos. Dice Homero

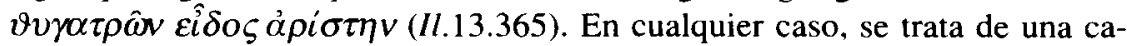
racterística física, sin indicación de cualidad sobrenatural alguna.

b) El pacto matrimonial: En contra de las versiones posteriores que indican que Casandra se mantuvo virgen a causa de su relación con Apolo ${ }^{3}$, en Homero el personaje no presenta una virginidad consagrada, sino que la hija de Príamo es pretendida por el caudillo Otrioneo $(H .3 .365)$ y se concierta un pacto matrimonial sin regalos ( $\alpha \dot{v} \varepsilon \delta v o v$ ), a cambio del cual Otrioneo promete ayudar al ejército troyano a vencer a los aqueos. Efectivamente, Príamo con-

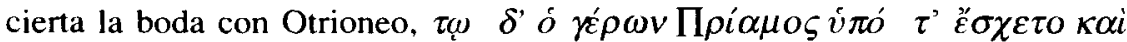

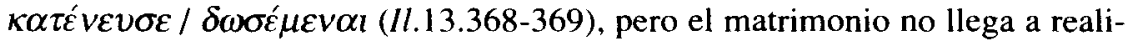
zarse, pues Otrioneo muere en la batalla a manos del cretense Idomeneo.

c) El avistamiento del cadáver de Héctor: Casandra es la primera en divisar (Il.24.697 y ss.) a Príamo, que retorna a Troya con el cadáver de Héctor, con los consiguiente gritos rituales ( $\kappa \dot{\omega} \kappa v \sigma \varepsilon v$ ) y lamentos ( $\gamma \varepsilon ́ \gamma \omega v \varepsilon$ ). Quizás el hecho de ser la primera en divisarlo y anunciarlo a sus conciudadanos es ya el embrión de la clarividencia que caracterizará al personaje en la literatura posterior ${ }^{4}$.

d) Su muerte junto a Agamenón: En Od. 11, en el pasaje del descenso de Ulises al Hades, éste habla con el espectro de Agamenón, quien narra su propia muerte junto a la princesa troyana a manos de Clitemnestra, con lo que ya desde el texto homérico, se encuentra unida la suerte de Casandra a la del caudillo Atrida. Este es el único rasgo significativo que desde Homero pasará a la tradición posterior, encabezada por Esquilo, respecto al personaje de Casandra.

\subsection{El ciclo épico}

Dentro de la épica arcaica no homérica dos son los rasgos que se destacan sobre la figura del personaje:

${ }^{3}$ Las dos versiones más comunes del mito son que Casandra rechazó los amores de Apolo y como castigo el dios la privó de la persuasión (asî Esquilo, Ag. 1202-1212, Apolodoro III 12, 5; Higino, Fab. 93; Schol. Lyc. p. 7, I. 27-33 Scheer, Servio, Aen. II 247. y Myth. Vat. 1 180, 11 196) y que Casandra es recompensada por Apolo con el don de la virginidad (Eurípides, Troad. 253-254).

4 Observo que esta idea se ha valorado muy recientemente desde el punto de vista del léxico por VEGA VEGA, M. a DEL MAR, «Casandra y su vocabulario mágico en Homero y Esquilo», Actas del X Congreso Español de Estudios Clásicos (21-25 de septiembre de 1999). Volumen 1, pp. 657 . 663 y esp. 661-663. 
a) La violencia de Ayax Oileo sobre Casandra. En la lliupersis o Saco de Troya se hacía esta referencia sobre la hija de Príamo. En el resumen que Proclo nos ha conservado del perdido poema épico se nos dice que, tras la toma de Ilión por los griegos, Ayax Oileo arrastra violentamente a Casandra del altar de Atenea donde se había refugiado, y, en su impulso, hace temblar la estatua de la diosa, por lo que incurre en sacrilegio. Es la primera vez que en la literatura griega se hace referencia a la profanación del templo de Atenea por obra de Ayax y a su violencia sobre Casandra, si bien aquí no se trata de una violencia de carácter sexual como indicarán fuentes posteriores.

b) La falta de persuasión. Casandra y Laocoonte advierten inútilmente a los troyanos sobre el peligro que encierra el caballo de madera. Así se nos cuenta en dos capítulos del Pseudo-Apolodoro cuya fuente última debe de ser el Saco de Troya. Las advertencias de Casandra no son atendidas, por lo que se desencadena la subsiguiente desgracia para los troyanos. En este texto nos aparece por primera vez la figura de Casandra en su vertiente profética que tan utilizada será después en la tragedia ática. En este mismo sentido cabe destacar cómo la Cipríada informa sobre las dotes mánticas de Casandra (Koi $K \alpha \sigma \sigma \alpha \dot{v} \delta \rho \alpha \pi \varepsilon \rho i$ $\tau \hat{\omega} v \mu \varepsilon \lambda \lambda \hat{o} v \tau \omega v \pi \rho o \delta \eta \lambda o \hat{\imath})^{5}$, como sucederá posteriormente en la lírica ${ }^{6}$.

A partir de los primeros testimonios que nos hablan del personaje mítico de Casandra en la literatura griega, podemos concluir que en su origen éste se caracteriza por el tema de la profecía y está ligado a la caída de Troya y al fin del Atrida Agamenón.

\section{CASANDRA EN El teatro griego: Esquilo y Eurípides}

De las obras conservadas de los tres grandes trágicos griegos sólo el $\mathrm{Aga}$ menón de Esquilo y Las Troyanas de Eurípides nos presentan a Casandra entre sus personajes, aparte de algunas referencias esporádicas en Hécuba 827 , Electra 1032, Ifigenia en Aulide 757 ss., Andrómaca 296 ss. y Alejandro fr. 9 Page, de este mismo autor. Es destacable, si comparamos el texto de Agamenón y el de Las Troyanas, la clara evolución del personaje de Casandra y la distinta utilización que cada autor hace del mito en función de sus planteamientos

5 Para un rastreo exhaustivo de las posibles referencias perdidas al mito de Casandra en el ciclo épico cf. MASON art. cit. pp. 81 y ss.

' La aparición de la figura de Casandra en este género se limita a las menciones en Baquílides fr. VIII, Ibico fr. 16 D y Píndaro Pyth. XI. 
ideológicos, motivados, principalmente, por las circunstancias históricas que les tocó vivir. Esto lo vamos a comprobar tanto en la diferente caracterización del personaje, como en las variaciones del argumento mítico.

\subsection{Esquilo}

En el año 458 a.C. Esquilo triunfa en los concursos trágicos con la representación de su trilogía la Orestíada. Esquilo escribe en plena época de esplendor de una Grecia que ha vencido al invasor persa y su obra está marcada por un espíritu religioso que exalta los valores establecidos, a saber, la democracia, la justicia refrendada por Zeus y el orden social y familiar representado por el matrimonio. En esta idea habrá que interpretar su versión mítica de la antigua leyenda de la muerte de Agamenón a manos de su esposa y de la posterior venganza de su hijo Orestes. También bajo ese prisma es preciso comprender el personaje de Casandra, que en el Agamenón aparece dotada ya de sus atribuciones habituales en la tradición posterior, a saber, el don de profecía y su relación con el dios Apolo, las cuales tendrán gran importancia en el desarrollo de la acción dramática. Las características particulares que Esquilo atribuye a este personaje mítico se pueden concretar como sigue:

a) Aspecto (ornamentos de profetisa) y actuación (silencio obstinado, éxtasis profético) de Casandra, que la caracterizan como un personaje de orden superior. Efectivamente, la figura de la profetisa que presenta Esquilo está ya muy alejada de la que veíamos en Homero: aquí se trata de una mujer extraordinaria que está en el umbral entre lo humano y lo divino, según muestra su apariencia física y su actuación: la aparición de Casandra en escena, en una de las impresionantes escenas tan del gusto esquileo, acurrucada en el carro de Agamenón, como concubina del Atrida y futura esclava de su casa, contrasta fuertemente con los ornamentos proféticos de los que está investida, las ínfulas y el cetro de Apolo. Respecto a su actitud, el silencio obstinado con que responde a las preguntas de Clitemnestra y del coro (a menudo justificado por los críticos por la dificultad del empleo incipiente del tercer actor por parte de Esquilo), es en realidad un procedimiento escénico mediante el que se acentúa el carácter excepcional del personaje antes de su caída en el éxtasis profético que tan importante papel desempeñará en el desarrollo de la obra ${ }^{7}$. En efecto, las profecías de Casandra permiten una movilidad temporal difícil de lograr en

${ }^{7}$ Para la función de la profecía en el teatro de Esquilo cf. ViCAIRE, P. (1963), «Pressentiments, présages, prophéties dans Eschyle», REG 76, pp. 337-357. 
el teatro, ya que consiguen que el espectador tenga acceso al conocimiento del tiempo pasado (los crímenes de la casa de Atreo) y al futuro más inmediato (la muerte de Agamenón y de la propia Casandra a manos de Clitemnestra). La profecía se repite dos veces: una primera, en pleno delirio profético, con un lenguaje que el coro no logra comprender (formalmente un canto epirremático en el que Casandra canta y el coro recita); la segunda se corresponde con una Casandra ya serena, que va a hablar «no a través del velo, como una novia recién casada», sino en palabras claras, pero que tampoco serán creídas, por culpa del castigo de Apolo, la falta de persuasión de la profetisa.

b) Apariencia de locura, pero mantenimiento de la solemnidad y dignidad. Podemos decir que toda la intervención del personaje está marcada por la solemnidad, incluso su estado de posesión. Así, en su intervención, Clitemnestra afirma que Casandra no está en su sano juicio y que sólo atiende a su

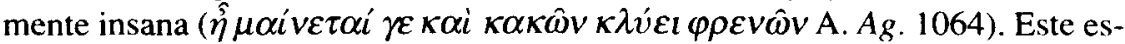
tado está marcado al principio por el silencio, después por el discurso extático, lejos, como veremos, de la posesión de la Casandra euripidea. Finalmente, con la misma dignidad que ha caracterizado toda su intervención, Casandra, resignada a no ser creída ni aún en el umbral de la muerte, tras deshacerse de sus distintivos de profetisa, en postrera queja contra el dios, se dirige a las puertas de la casa, que marcarán su paso al más allá, en definitiva, al mundo de los inmortales.

c) Ejemplificación del tema de la culpa. La culpa que alcanza a Casandra es de dos tipos: colectiva e individual. Como telón de fondo se encuentra la culpa que mancha la estirpe de los Atridas, el festín sangriento de Atreo. Esa culpa heredada colectivamente alcanza a todos los habitantes de la casa y, por contaminación, también a la profetisa. Frente a esto, hay una serie de culpas individuales, de crímenes conscientes encadenados entre sí que sólo cesarán cuando la sentencia del Areópago ponga fin a la sucesión de venganzas. La culpa individual de Casandra, en este caso, sería su impiedad al engañar al dios Apolo. La inclusión de Apolo en la historia de Casandra no es extraña, dado el papel tan importante que desempeña el dios en toda la trilogía ${ }^{8}$. Precisamente, la versión del poeta sobre la relación entre el dios y la profetisa innova el mito tradicional, ya que ningún motivo induce a pensar que existiera una fuente anterior en la que el autor base la historia del amor de Apolo por la hija de Pría-

* Según hipótesis de Wilamowitz, la significación de Apolo en el tema mítico de la Orestíada proviene de la antigua poesía épica de influencia délfica, cf. LeSKy, A. (1976), Historia de la Literatura Griega, Madrid, Gredos, p. 284. 
mo, tal como aparece en $A g .1203-1215^{\circ}$, y puede entenderse que la innovación obedezca al deseo de incluir una impiedad que justifique el castigo final del personaje.

d) Ejemplificación del tema del aprendizaje por el sufrimiento. En este sentido, es justificable también la inclusión de este mito para ejemplarizar el

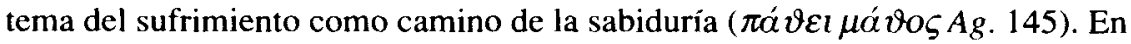
el largo camino desde princesa troyana a prisionera y concubina que va a morir lejos de su patria, desde joven impía que traiciona a Apolo a profetisa consciente de su propia destrucción, hay todo un proceso de adquisición del conocimiento. Por tanto, el tema destacado por Esquilo en el mito son los sufrimientos de Casandra desde su engaño al dios: la falta de credibilidad ante sus conciudadanos (vs. 1210-1212), los nuevos vaticinios sobre la casa de Atreo y el crimen inminente que se suceden a lo largo de la escena y que tampoco van a ser creídos, en este caso, por el coro. Finalmente, Casandra llega al

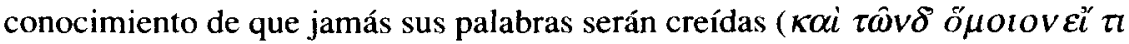
$\mu \dot{\eta} \pi \varepsilon i \vartheta \omega \mathrm{vs.} 1239$ ), y llega asimismo a la aceptación de su propio destino, por lo que, tras romper los atributos divinos, se dirige serena hacia la muerte. En un momento anterior a la entrada de Casandra en el palacio, el coro la califica como «muy desgraciada y muy sabia» $\hat{\omega} \pi o \lambda \lambda \dot{\alpha} \mu \dot{\varepsilon} v \tau \dot{\alpha} \lambda \alpha \iota v \alpha, \pi o \lambda \lambda \dot{\alpha} \delta \alpha \hat{v}$ $\sigma o \varphi \eta^{\prime} / \gamma^{\prime} v \alpha t$ (A. Ag. 1295-1296), ambos conceptos, sufrimiento y sabiduría, unidos en la persona de la profetisa como ejemplificación de esta idea básica de Esquilo que es el apredizaje por el sufrimiento.

e) Ejemplificación de la fidelidad siervo-señor. También en la actitud de Casandra con respecto a Agamenón se puede observar una característica propia en el personaje en Esquilo: se puede decir que la concubina es fiel a su señor, por oposición a la esposa legítima que lo traiciona. Tiene hacia Agamenón una actitud reverente, le llama «mi señor» $\tau \tilde{\omega} \mu o \lambda o ́ v \tau \imath \delta \varepsilon \sigma \pi o ́ \tau \eta / \dot{\varepsilon} \mu \tilde{\omega}$ (A. Ag. 1225), y en una de las metáforas tan del gusto del autor lo califica de «no-

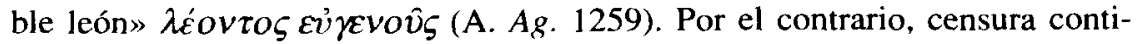
nuamente la traición de Clitemnestra (la llega a llamar «perra odiosa» ov $\kappa$ oí $\delta \varepsilon v$ oï $\alpha \gamma \lambda \omega ́ \sigma \sigma \alpha, \mu t \sigma \eta \tau \hat{\eta} \varsigma \kappa v v \dot{\varsigma} \varsigma$ (A. Ag. 1228) y, finalmente, asegura que

${ }^{9}$ Mason, P.G., art. cit. p. 85 deja abierta la posibilidad de que la historia del amor de Apolo por Casandra sea invención del propio Esquilo, aunque también admite que podría ser, por su esquema asociado al primitivo concepto de inspiración, una versión mítica popular, como la recogida por Eustacio (a Hom. 663.40) en la que se narra que Casandra y su hermano Héleno fueron dejados de niños en el templo de Apolo, donde una serpiente les lamió los oídos y recibieron el don de profecía. 


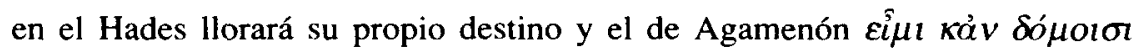

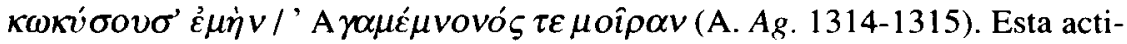
tud resignada y respetuosa viene condicionada por el pensamiento del autor, que en su obra hace una defensa de los valores establecidos, entre ellos, el matrimonio y la relación señor-esclavo. La oposición entre la Casandra fiel y la Clitemnestra adúltera se resumirá en la petición final de la profetisa al coro de ancianos argivos: su testimonio, cuando llegue el momento, de que a cambio de la mujer que ahora muere, morirá después la esposa culpable ( $\check{\tau} \tau \alpha v \gamma v \dot{\eta}$

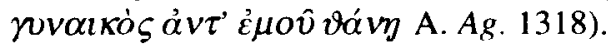

\subsection{Eurípides}

Un panorama muy diferente encontramos en Eurípides. El poeta ya no es el hombre de Platea y Salamina que ha conocido las grandes victorias griegas, sino un hombre marcado por el racionalismo de la época y por el trauma de la Guerra del Peloponeso. Precisamente, Las Troyanas la compone en el año 415, en medio del ambiente pesimista que se respira por el difícil desarrollo de la contienda y esto se plasma en el cuadro de las desgracias que la guerra acarrea a vencedores y vencidos, según aparece en la obra. Para ello toma la figura de las prisioneras troyanas que esperan ser repartidas entre los vencedores y, entre ellas, la de Casandra. La presentación de su figura viene marcada por los siguientes rasgos:

a) Apariencia de ménade y términos que la designan como tal: La caracterización de Casandra en Eurípides dista mucho de la figura majestuosa y serena que aparecía en Esquilo. Su presencia en escena, en el campamento griego donde están las prisioneras troyanas, está precedida por una conversación de Hécuba y el heraldo Taltibio, quien anuncia la suerte de la profetisa: ser compañera de lecho de Agamenón. Desde esta primera conversación se designa a Casandra con términos que hacen referencia a lo dionisíaco y que la caracterizarán como un personaje fuera de lo común: Hécuba se refiere a ella como «dominada por el fu-

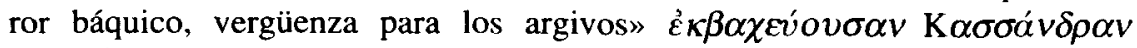

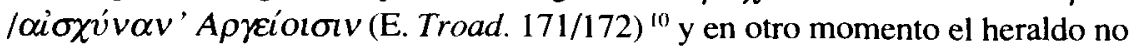
comprende cómo el jefe Atrida ha podido elegir para su lecho una mujer a la que «Apolo enloqueció el pensamiento» $\varepsilon \dot{i} \mu \eta^{\prime} \sigma^{\prime}$ 'A $\pi \dot{\lambda} \lambda \lambda \omega v \varepsilon^{\prime} \xi \varepsilon \beta \alpha_{\alpha} \kappa \chi \varepsilon v \sigma \varepsilon v \varphi \rho \varepsilon ́ v \alpha \varsigma$

${ }^{10}$ Sobre la condición marginal del personaje que implica esta expresión cf. IRIARTE, A. (1990), Las redes del enigma. Voces femeninas en el pensamiento griego, Madrid, Taurus, p. 106. 
(E. Troad. 408). Esta condición marginal rayana en la locura tiene una connotación religiosa que se hace explícita en la repetición del verbo $\beta \dot{\alpha} \kappa \chi \varepsilon v \omega$ y en la designación que Hécuba hace de Casandra como «acompañante de los dioses en el frenesí báquico» $\hat{\omega} \sigma o ̛ j \beta \alpha \kappa \chi \varepsilon K \alpha \sigma \sigma \alpha \dot{v} \delta \rho \alpha \vartheta \varepsilon o \hat{\varsigma} \varsigma$ (E. Troad. 500). En efecto, la figura de Casandra, que aparece en escena corriendo y, en pleno furor de una danza salvaje, entona un canto de Himeneo por su forzado concubinato con Agamenón, parece la precursora de las Bacantes euripideas ".

\section{b) Ausencia de huellas del engaño con el que Casandra ofende a Apo-} lo. La virginidad como recompensa: La relación de la profetisa con Apolo se caracteriza por la dedicación de la doncella al dios. Para ella, pues, la virginidad sería una recompensa por su consagración a la divinidad: $\hat{\eta} \tau \dot{\alpha} v \tau o \hat{v}$

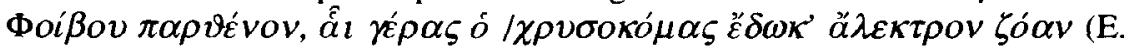
Troad. 253-254). En este mismo sentido, en la escena en que Casandra se deshace de su atavío de sacerdotisa, podemos observar la diferencia que existe con la escena paralela de Esquilo: en aquella la profetisa reniega del dios que la ha perdido y de sus atributos, aquí Casandra se despide tristemente de las insig-

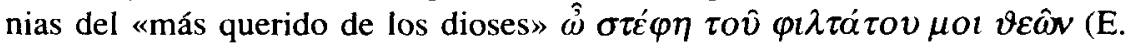
Troad. 451), y, a la vez, de la virginidad que le tenía ofrendada, «ahora que mi

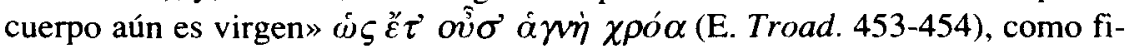
nal del himeneo que ha entonado (recuérdense los epitalamios de Safo donde la novia se despide de su virginidad) ${ }^{12}$.

En efecto, el tema de la virginidad de Casandra tiene su importancia puesto que la tradición posterior ha transmitido que Ayax Oileo la violó junto a la estatua de Atenea en Troya. No aparece esta versión en Eurípides, quien, si bien hace alusión a la violencia de Ayax sobre Casandra junto a la imagen de

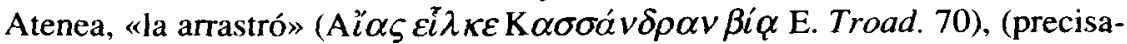
mente por ello la diosa deja de proteger a los aqueos, según cuenta ella misma a Poseidón en el prólogo de Las Troyanas), no presenta, sin embargo, argumentos para entender en la presencia del verbo $\tilde{\varepsilon} \lambda \kappa \omega$ ningún matiz sexual ${ }^{13}$. Pero si entendemos, sin embargo, que el mito de Casandra está incluido en Las

$"$ Es preciso destacar en este punto que el acercamiento entre el culto de Apolo y Dioniso, como dioses ambos de la posesión, es un hecho histórico que explica que Casandra, vinculada a Apolo al menos desde Esquilo, aparezca en Eurípides dotada de las características propias de una bacante. De hecho, este sincretismo religiosos tiene una manifestación en la construcción de un altar a Dioniso en Delfos.

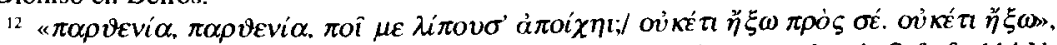
«Virginidad, virginidad ¿dónde te vas y me dejas?/ya no volveré a tí, ya no volveré» Safo fr. $114 \mathrm{~V}$.

${ }_{13}$ MASON, art.cit. considera que, de haber sido Casandra previamente violada por Ayax Oileo, no habría sido entregada después como concubina al jefe Atrida. 
Troyanas de Eurípides para ejemplificar el horror de la guerra en las mujeres de los vencidos, es natural que el autor muestre las vejaciones a que son sometidas y, aunque no se menciona la violación de Oileo, sí se destaca el patetismo de la antigua princesa y sacerdotisa obligada a compartir el lecho con el vencedor, a «celebrar un matrimonio a punta de lanza bajo las armas argivas»

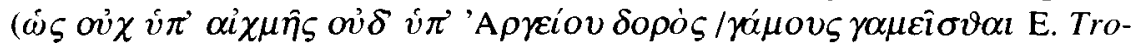
ad. 346-347), en palabras de Hécuba.

c) La relación entre Casandra y Agamenón: El odio al vencedor: También en la relación Agamenón-Casandra se observan notables diferencias con el texto de Esquilo. En éste veíamos en Casandra una esclava y concubina que, respetuosa para con su señor, lamenta la inevitable muerte del Atrida. En Eurípides, Casandra, la ménade, entona un himeneo triunfal porque mediante sus forzadas relaciones con Agamenón va a llevar la ruina a la casa de los Atridas: «Voy a matarlo, voy a arruinar su casa en venganza por mis hermanos y

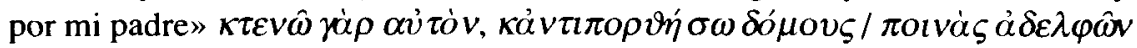

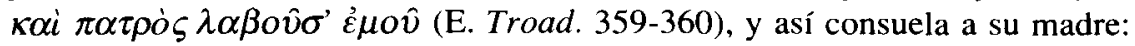
«Por esto, madre, no tienes que lamentarte por tu tierra y por mi lecho, pues con mis bodas voy a destruir a nuestros más odiados enemigos» $\hat{\omega} v$ ơv $v \varepsilon \kappa^{\prime}$ ov

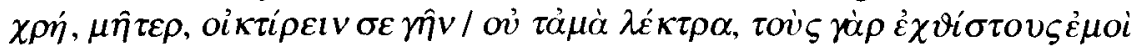

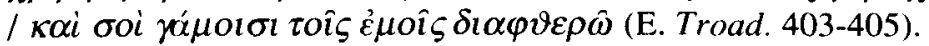

Para concluir este punto diremos que, frente a la Casandra de la Orestíada que afronta la muerte pesarosa pero serena, la Casandra de Las Troyanas se dirige a la muerte rebosante de odio para con el enemigo invasor, pero feliz porque su ruina conlleva también la ruina de la casa de Atreo.

No se cierra en la literatura griega la aparición de la figura de Casandra con el texto del último de los trágicos. Aparte de mitógrafos como Apolodoro, que cuentan diversas versiones del mito, tenemos la obra del alejandrino Licofrón de Calcis, Alejandra, poema en trímetros yámbicos de estilo oracular y oscura interpretación, que le hizo acreedor del nombre de tò $\sigma \kappa o \tau \varepsilon t v o ́ v \pi o i ́ \eta \mu \alpha$ "poema oscuro". En él Alejandra es Casandra, la hija de Príamo, cuyo padre, disgustado por las dotes proféticas de su hija, la habría hecho encerrar. La muchacha hace una sucesión de profecías que van desde la caída de Troya, de acuerdo con la versión mítica tradicional, hasta cuestiones políticas de la propia época del autor, con especial importancia respecto a las predicciones que tienen que ver con la figura de Alejandro Magno, con la posterior lucha de Oriente y Occidente que dará lugar a la constitución del Imperio Romano cuya ascendencia troyana intenta justificar el poema.

A partir de la Edad Media, la figura de Casandra entra en la literatura europea ligada a la guerra de Troya, como prototipo de la mujer sensata que des- 
taca por su castidad y doncellez frente a la figura de Helena, encarnación del mal ${ }^{14}$. Ya en el siglo XX, desde la peculiar interpretación del personaje que hace Pérez Galdós en las letras españolas ${ }^{15}$, pasando por la lectura política que permiten Las Troyanas en la adaptación que de Eurípides hiciera Jean Paul Sartre ${ }^{16}$, llegamos a una de las obras que más notoriedad ha dado a la figura de Casandra, desde los trágicos griegos, la novela Kassandra de la escritora alemana Christa Wolf.

\section{La Casandra de Christa Wolf: \\ NUEVA LECTURA DE LOS TEXTOS CLÁSICOS}

Christa Wolf, filóloga, periodista y una de las escritoras más reputadas de la Alemania actual, publica a comienzo de los años ochenta su novela Kassan$d r a$, cuya traducción española vio la luz en $1984^{17}$. Una vez más, un escritor

${ }^{14}$ Así, desde Boccaccio (De claris mulieribus, Filostrato) el personaje está ligado al argumento de Troilo y Cresida, como sucederá posteriormente en Chaucer y Shakespeare. Siguiendo la tradición clásica que presenta la imagen de una Casandra profetisa, en El auto de la Sibila Casandra de Gil Vicente se la equipara con las Sibilas. Por primera vez Casandra es protagonista en el poema dramático de Schiller Kassandra (1802). Cf. Frenzel, E. (1976) s.v. Casandra.

is En la literatura española cabe destacar el drama que Pérez Galdós estrena en 1910, Casandra, aunque ya había sido publicado en forma de novela en cinco jornadas el año 1905 (Madrid. Perlado, Páez y Compañía, 1905). Si bien no se trata de un drama de corte histórico, el nominalismo de los personajes (Casandra y sus hijos Héctor y Aquiles) permite ver, no obstante, conexiones con el mito clásico. La protagonista, Casandra, una mujer de comienzos del siglo XX, tiene en común con la profetisa troyana su carácter marginal de mujer amancebada y madre soltera en la sociedad de 1910, su capacidad para predecir y lamentar desgracias futuras, y la denuncia desde su marginalidad de una situación injusta provocada por un poder corrupto, en este caso, un celo religioso hipócrita. Como la Casandra de Eurípides destruye el poder de la casa de Atreo, así también la galdosiana llevará la muerte a la cruel marquesa de Berzosa. La expectación social que provocó el estreno de la obra y la manifestación de carácter político producida a la salida del teatro la propia noche del estreno muetran una vez más que el viejo mito pudo ser utilizada para poner de manifiesto un problema presente en la España de 1910. La documentación histórica la hemos tomado de Los estrenos teatrales de Galdós en la crítica de su tiempo, Madrid, Consjería de Cultura de la Comunidad de Madrid, 1988.

${ }^{16}$ Para la pervivencia de Eurípides en en el teatro francés cf. RomiLly, J. de (1986), La modernité d'É Euripide, París.

17 Publicada por la editorial Alfaguara (Ch.Wolf, Casandra. Madrid, Alfaguara, 1984), edición por la que citaremos la obra a lo largo de este trabajo. Esta misma editorial manifestó en su momento la intención de publicar también las cuatro conferencias de la autora que acompañaban a la versión alemana de la obra, Voraussetzungen einer Erzäblung:Kassandra, pero no llegó a llevarla a cabo.

En 1990 publicamos un primer trabajo sobre la presencia de los clásicos en la novela de Christa Wolf, Cf. HLALDE, P. (1990), "La figura mítica de Casandra: del teatro clásico a la litera- 
actual se sirve del antiguo mito para ilustramos acerca de la realidad del momento. Básicamente, la autora se sirve de la vieja historia de la guerra de Troya para hablarnos de los problemas políticos y sociales de la Europa de su época, en el momento previo a la apertura de los países del Este. La propia conciencia que tiene Wolf de su utilización del mito la lleva a afirmar que que su Kassandra no es una novela «histórica» como tal, sino que surge de la realidad presente y tiene su punto de partida en el peligro de guerra permanente en que vive la Europa de bloques del momento en que se escribe la obra' ${ }^{18}$. No obstante, las posibles lecturas de la novela no acaban ahí, así como los temas sobre los que la escritora reflexiona: el poder, la condición de la mujer, la necesidad de héroes, el poder de la palabra.

La documentación mitográfica que utiliza Wolf es muy extensa: recoge prácticamente todas las variantes del mito de Casandra ${ }^{19}$, y de la concatenación de las mismas y la adición de elementos propios va surgiendo la trama de la novela. Veamos, pues, aquí las diferencias y concomitancias de la Casandra de Wolf con la que nos han transmitido los textos clásicos:

tura contemporánea», en Actas del $2{ }^{\circ}$ Coloquio de Estudiantes de Filología Clasica. Universidad Abierta Serie $R-n .^{\circ}$, pp. 13-34. Otros artículos sobre esta novela son el de BARJAU, Eustaquio (1994), «Mito sobre mito (a propósito de Kassandra de Christa Wolf)», Revista de Occidente, 158 159, pp. 59-65; el de BALZER, BERIT (1994), «Casandra, entre mito y mujer», Actas del IX Simposio de la Sociedad Española de Literatura General y Comparada. Tomo I: La Mujer: Elogio y vituperio, Zaragoza, pp. 162-175, el de SiguÁN, MARISA (1994), «Hablar con mi propia voz:lo máximo. Mitología y feminismo en la Casandra de Christa Wolf», en Mujeres y Literatura, A. Carabó y E.Sagarra eds., Barcelona, PPU y el de Garcia Gual, Carlos (1995), «Acerca de Casandra de Christa Wolf», Humanitas 47, pp. 1119-1132.

18 Para las declaraciones de la autora cf. la entrevista hecha por El País del 27 de noviembre de 1986, bajo el epígrafe «El placer de la destrucción. Entrevista con Christa Wolf».

${ }_{19}$ Elementos del ciclo épico; de Esquilo (la propia aparición de Casandra, en este caso ante el palacio de Micenas, incluso la mención de la alfombra púrpura que Clitemnestra tiende a la entrada de su esposo en el Agamenón de Esquilo: "Tropezó con la alfombra roja, como un buey en el matadero» (p. 54); de Eurípides (sobre todo el tema del sufrimiento femenino, de las mujeres como auténticas víctimas de los hombres: «El mundo habitado [...] se había vuelto cada vez más cruelmente, cada vez más deprisa contra nosotras» (p. 140); de Licofrón toma el tema del encierro de Casandra en una cesta; recoge Wolf asimismo versiones posteriores como el reconocimiento de Paris como hijo de Príamo, tomado de Apolodoro, o el episodio de Héleno y Casandra niños, cuando la serpiente les lamió los oídos en el templo de Apolo, tomado de Higino, por poner algunos ejemplos significativos.

Es destacable el tratamiento del mito de Helena, en el que la autora alemana retoma la tradición que parte de la Palinodia de Estesícoro (que también conoce Heródoto H, 112), según la cual Helena nunca estuvo en Troya. La «sombra» de Helena que, según algunos autores griegos, fue lo que realmente estuvo en Ilión, sirve a Wolf para ilustrar las falsas excusas que dan lugar a las guerras. Por el contrario, una de las innovaciones más llamativas del mito es la supuesta relación amorosa entre Casandra y Eneas. 
a) El tempo de Esquilo: En la propia presentación de Casandra encontramos el primer eco esquileo: como en la Orestiada la novela de Wolf recoge el momento en que la hija de Príamo llega como cautiva, en este caso, ante el palacio de Micenas, en lugar del de Argos. En el intervalo de tiempo entre la entrada de Agamenón en el palacio y la entrada de la propia Casandra, ésta, que comprende que Clitemnestra no va a perdonarle la vida, rememora los acontecimientos de su vida pasada hasta su presente destino de esclava. El tiempo de este recuerdo coincide así con el tiempo de silencio dramático de la Casandra de Esquilo, y también aquí, como en la tragedia, Casandra adquiere, en el momento previo a su muerte, el grado máximo de conocimiento, el punto más alto de elevación moral.

b) El sacerdocio: está incluido en la novela como medio para conseguir el poder en un mundo de hombres que relega a las mujeres. La protagonista comienza rememorando su primera juventud y con ello se introduce en la novela el tema del sacerdocio de Apolo y del don de profecía. Este tema esta incluido en la novela en función de la ambición de la profetisa, quien desde el estado de elevación social que le confiere ser la hija favorita de Príamo, sin embargo se ve relegada a un segundo plano en un mundo de hombres en el que la política está prácticamente vedada para la mujer: «Era una pena, una verdadera pena, que yo no pudiera sentarme por la mañana en el consejo, en su lugar y con sus vestidos, en el sillón de ancho respaldo» ( $p$. 57). El sacerdocio es la única vía que permite canalizar la ambición de poder e influencia manifestada por Casandra: «...mi deseo de tener influencia en las personas ¿de qué otra manera podría dominar una mujer?» (p. 37). En determinado momento incluso llega a renegar de una condición femenina que la limita, y, envidiosa de su hermano Héleno, el arúspice, comenta: «Cómo deseaba estar en su lugar, qué era una sacerdotisa comparada con un arúspice [...] si pudiera cambiar mi sexo por el suyo, si pudiera negar mi sexo, esconderlo» (p. 38) ${ }^{20}$.

20 Sobre la relegación de la figura femenina frente a un hermano varón trata Woolf, VIRGINIA (1981) en A room of one's own, London, Granada, concretamente, en el capítulo III dedicado a la hermana de Shakespeare. También la escritora británica, en este mismo libro, p. 43, cita la obra de F.L. Lucas Tragedy, quien habla de la paradoja que supone que las grandes figuras (entre las que, por cierto, menciona a Casandra) del teatro de Eurípides sean mujeres, pese a lo que él califica de «misoginia» en este autor. Un curioso dato que proporciona V. Woolf en su obra (p. $54 \mathrm{y} \mathrm{n}$.) es la existencia de un ensayo de Florence Nightingale titulado «Cassandra» y publicado en The Cause por R.Strachey, en el que abogaba por un acceso pleno de la mujer a la cultura y no restringido a las reuniones «femeninas» de la época, donde únicamente se recitaban lacrimógenos poemas. $F$. Nightingale (1820-1910) fue una enfermera y escritora británica que profes 6 una peculiar forma de feminismo que intentó conciliar con sus raíces cristianas. 
c) La virginidad: La parthenía de Casandra es otro elemento que en el mito tradicional está unido al tema del sacerdocio. La versión de Christa Wolf es innovadora en este punto y el sacerdocio no es sinónimo de virginidad, sino de posibilidad de huida de unas relaciones sexuales impuestas, que humillan a la protagonista, que le producen «aversión a las aproximaciones de los hombres mortales» (p. 37) y supone una mayor libertad de elección en este punto. En efecto, en la novela se nos presenta a Casandra como amante de Eneas, en una unión libre y enriquecedora, frente a la mujer controlada por los hombres, representada en la figura de Políxena.

d) La religiosidad: Christa Wolf nos presenta un personaje sin ideales místicos que evoluciona hasta la incredulidad. Su vocación de sacerdotisa carece de sentimientos religiosos y su trivial relación con Apolo se limita a la práctica del ritual: «Yo colaboré en el ritual como correspondía a mi oficio, servicios, gestos, palabras sin sentido...» (p. 105). Y así asistimos a la evolución de una Casandra escéptica que, conforme avanza la guerra, va dejando de creer en los dioses establecidos: «Porque entretanto había dejado de creer en los dioses» (p. 118) y se rebela ante una religión que únicamente supone un sustitutivo para la felicidad, mujeres que elevan sus lamentos ante unos dioses inoperantes: «En el templo rezaban con un fervor que no me gustaba, porque nuestro dios Apolo tenía que sustituir su vida robada» (p. 125). Es destacable la idea de unos dioses ajenos a la dolorida historia humana, que ya veíamos en Eurípides y que vuelve a tomar la autora alemana: igual que el gran trágico, Christa Wolf escribe en una época de crisis, de cuestionamiento de valores establecidos, y en ambos observamos una línea semejante de escepticismo.

La Casandra de Christa Wolf conoce, sin embargo, las nuevas tendencias religiosas de carácter mistérico que cultivan las mujeres humildes que viven en las orillas del Escamandro y podemos verla en algún momento de la obra en una danza convulsa, tal como la presentaba Eurípides caracterizada de ménade. La evolución moral de la protagonista está marcada por la guerra y por el trato con estas mujeres humildes: «¿Cuándo se derribó mi altivez hacia el dolor? Al empezar la guerra, naturalmente, desde que ví el miedo en los hombres» (p. 42); y en otro momento dice: «Las mujeres de las montañas me habían curado de mi arrogancia» (p. 97). La toma de contacto con la vida que se desarrolla fuera del reducido ámbito del palacio lleva a Casandra al conocimiento de distintas realidades coexistentes en la misma Troya: «Cuántas realidades había en Troya además de la mía, que yo había considerado la única» ( $p$. 30). De este acercamiento a las otras realidades surge su camino hacia otro tipo de clarividencia, como veíamos también en Esquilo, hacia la adquisición de la verdadera sabiduría. 
e) EI don de profecía: Se restringe a la interpretación ajena de un sueño de Casandra en su adolescencia: la visión onírica de Apolo hace que se propague su fama como profetisa. Sus profecías no aparecen dictadas por los dioses sino por su percepción de la realidad y por su elaboración intelectiva de los hechos, lo que podríamos llamar un caso especial de «intuición femenina». Uno de los ejemplos más claros es el de la profecía de su propia muerte, por poner un ejemplo visto ya en Esquilo y Eurípides: Casandra, a su llegada a Micenas, intuye que va a ser asesinada, pero es la visión de Clitemnestra y el conocimiento del carácter de ésta lo que la lleva a su fatal convencimiento: «Como no sólo conozco a los hombres, sino, lo que es más difícil, también a las mujeres, sé que la reina no puede perdonarme la vida» (p. 18).

f) La locura: Se manifiesta al mismo tiempo que su decadencia social, pero en ese momento el personaje adquiere la auténtica clarividencia. Asi comenzarán para Casandra unas manifestaciones esporádicas de «anormalidad», a medias entre la enfermedad y la locura, que supondrán el inicio de su marginación: «Se difundió con la velocidad del viento el rumor de que estaba loca» (p. 75). En la novela asistimos, de esta manera, al descenso social de la protagonista y a su caída en un estado marginal, en la «locura» que, como vimos, caracteriza al personaje ya desde los trágicos griegos: «La demencia como final del tormento de la simulación» (p. 75), y siempre en la idea de que la persona que a los ojos de los demás cae en la locura es la que adquiere auténtica clarividencia.

g) El tema del sufrimiento femenino: Como en Eurípides, está tratado extensamente. Las mujeres son las verdaderas víctimas de la guerra: «Los hombres de ambos bandos parecían aliados contra nuestras mujeres» (p. 125). La filosofía de estas mujeres ante el conflicto puede resumirse en la frase de una de ellas: «Entre morir y matar hay una tercera posibilidad: vivir» (p. 141). Esta postura es la adoptada por los elementos femeninos de la novela y por los dos únicos personajes masculinos caracterizados de forma totalmente positiva: Eneas y su padre Anquises, figuras también marginales, refugiados en las montañas, para los que un combate estéril carece de sentido: ellos apostarán por la vida y marcharán lejos para fundar la nueva Troya. Especialmente conmovedor es el pasaje previo al final de la novela, en el que Casandra narra su despedida de Eneas. La joven sacerdotisa no quiere acompañar a su amante en la huida, en el exilio, pero no, como podría pensarse, por fidelidad a una patria que ya no existe, sino por su escepticismo sobre la excelencia de sistema alguno, sobre la debilidad de la condición humana, sobre el poder, sobre la existencia y necesidad de héroes: «No puedo amar a un héroe» (p. 163). 
5. Cassandra. Princess of Troy, de Hilary Bailey:

UNA LECTURA HISTORICISTA DEL MITO

En 1996 ve la luz la traducción española de la novela Cassandra. Princess of Troy, publicada en su versión inglesa en $1993^{21}$. De nuevo encontramos como protagonista de una obra a la antigua princesa troyana, si bien, en este caso, Hilary Bailey, autora de best sellers, presenta un tono muy distinto al que habíamos visto en la novela de Christa Wolf. En esta ocasión nos encontramos ante una novela histórica, sin que se pueda ver, al menos de forma evidente, una lectura trascendente, con posiciones programáticas como las que habíamos visto en la autora alemana con respecto a temas como el feminismo o el pacifismo.

Si por otra cosa llama la atención es por la alteración (en ocasiones violenta) de los hechos narrados por las fuentes clásicas (que, como vimos, Wolf respeta, combina y conoce exhaustivamente), en aras de una visión «historicista» de los hechos de Troya. Así, junto al adulterio de Helena, aparecen las luchas comerciales por el dominio de los enclaves portuarios de Asia Menor entre micénicos y asiáticos, y, de telón de fondo omnipresente, la importancia del imperio hitita y de su monarca Suppiluliumas, así como, en el sorprendente final de la narración, el hundimiento del imperio micénico a manos de los «pueblos del mar». Si bien la novela cuenta con un apéndice final, Nota de la autora, en el que se da cuenta de las fuentes utilizadas, para las que señala la Ilíada, «lo que los dramaturgos griegos, basados en viejas leyendas, escribieron sobre la guerra y sus secuelas doscientos años después que Homero» (!!) y la «obra de Virgilio» (se entiende que la Eneida), sin embargo, al adentrarse uno en el texto de la novela, muy mal se puede ver el seguimiento de dichas fuentes, si no es en líneas muy generales ${ }^{22}$. Así, la obra nos presenta a una sorprendente Casandra, viuda de un granjero griego y escondida bajo una falsa identidad en algún lugar de Tesalia ${ }^{23}$. Allí se produce el encuentro entre la pro-

${ }^{21}$ Citaremos por la versión española de la obra, Hilary Bailey, Casandra.Princesa de Troya. Emecé Editores. Barcelona, 1996. No conozco estudios particulares sobre esta novela. Sí tratan de ella Barrios, M.J. Barrios, M.J. Durán, B. (2001), «Arquetipos femeninos en la novela histórica grecolatina», EC 43 (2001), 7-36, esp. 24.

${ }^{22}$ Sin embargo, en pequeños detalles a lo largo de la narración se pueden ver aspectos muy concretos de los mitos asociados a la guerra de Troya, como cuando se dice que a Hécuba «los griegos la llaman perra y Reina de los Perros» (p. 22) o cuando, al final de la novela, se nos presenta a Héleno como marido de Andrómaca, la viuda de su hermano Héctor.

${ }^{23}$ No deja de ser sorprendente el pasaje donde Casandra, prisionera ante el palacio de Micenas espera su propia muerte tras la de Agamenón, tal y como nos narra el texto de Esquilo, y, de pronto, es salvada por la figura de un Eneas que en esta ficción es un tránsfuga pasado al bando micénico. 
tagonista y una Helena envejecida y marchita con la que recuerda tiempos pasados. Veamos, siguiendo los mismos elementos analizados en la novela de Wolf, las, en este caso, grandes diferencias y escasas concomitancias que presenta la Casandra de Bailey con la que nos legaron los textos clásicos:

a) El tempo de la obra: Si bien Hilary Bailey también hace uso, como Wolf, de la técnica del flash back, sin embargo, no se adapta como la alemana a lo que denominábamos el tempo de Esquilo. En este caso, la novela se organiza en torno a tres puntos espaciales, Troya, Micenas y Tesalia, de los que los dos primeros se corresponden a la narración del tiempo pasado (Troya se corresponde con los recuerdos de Casandra y Micenas con los de Helena, puestos, sin embargo, en boca de la ya muerta Clitemnestra). Curiosamente, el desarrollo de los hechos narrados en la novela tampoco se corresponde con el tempo de Homero, ya que la autora despacha el desarrollo de la Guerra de Troya en el plazo aproximado de un año, frente a los diez que le atribuyen las fuentes literarias clásicas.

b) El sacerdocio: Este elemento, esencial en la configuración de este personaje mítico tal y como nos lo legó Esquilo, está ausente en esta novela. Casandra nunca alcanzará la condición de sacerdotisa, si bien es cierto que, por sus dotes mánticas, Hécuba considera la posibilidad de hacer de ella la sucesora de la sibila de la ciudad, en este caso sacerdotisa de Hécate. Esta posibilidad es rechazada de plano por el más bien chato personaje de la protagonista quien ansía alcanzar el matrimonio: «Temía que mi madre me buscara y me llevara con ella a las ceremonias de aquella noche como sacerdotisa. Que sucediera esto siendo yo tan joven, equivalía a declarar que era la nueva augur (...). Tendría que estar en aquella cueva de la colina con mis visiones durante toda mi vida (...). Quería casarme, ver otras gentes, otros sitios, ser una reina en la corte de un gran rey» (pp. 77-78).

Una de las pocas concesiones que la autora hace a las versiones míticas legadas por la literatura griega, concretamente al Agamenón de Esquilo, es la del aspecto de Casandra a su llegada a Micenas. En esta escena la autora justifica la llegada de la protagonista a la ciudad con los ornamentos de sacerdotisa haciendo que sus captores le pongan casualmente los ropajes de la sibila troyana, muerta en la guerra: «Supongo que Agamenón no sabía, cuando registraba el botín que llevaba al palacio buscando un vestido, que el hábito que sacó era la vieja túnica ceremonial de la sibila de Troya (...). Debía de estar predestinado que me diera aquel vestido (...). Yo, que desde niña había intentado evitar convertirme en sibila, fuí forzada a asumir su ropa y su papel aquí, en Grecia, justo cuando estábamos a punto de entrar en la fortaleza de Agamenón» (p. 329). 
c) La virginidad: Tampoco esta novela mantiene este elemento constitutivo del personaje de Casandra en los clásicos y que, en definitiva, viene marcado por su relación con Apolo. Sin embargo, la relación amorosa de la protagonista con un marinero fenicio está incluida en la obra de manera más bien gratuita, sin que tenga mayor trascendencia en el desarrollo de la acción, y más bien parece que la autora pretende con ella dar un toque "romántico» al argumento de la novela. Por lo demás, la mención a un fugaz matrimonio de Casandra con el hijo de un aliado de Príamo es una oportunidad que, consciente o inconscientemente, deja pasar la autora para incluir el dato homérico de las frustradas nupcias de Casandra con Otrioneo: «La primavera siguiente estaba casada, contra mi voluntad, con el hijo de un aliado, para que mi suegro mantuviera a sus guerreros luchando a nuestro favor. (...) No diré el nombre de mi marido; el pobre murió en la batalla una semana después» (p. 129) ${ }^{24}$.

d) La religiosidad: Es quizá el elemento más Ilamativo de la novela, puesto que no sólo los dioses griegos, sino también su culto, están ausentes por completo de la obra ${ }^{25}$. Sólo Hécate, que aparece como diosa tutelar de Troya, y a la que la autora pretende identificar con la «diosa triple» adorada por ciertos pueblos de Oriente Medio ${ }^{26}$. La justificación que hace Bailey en su nota final resulta arriesgada al afirmar que los griegos de Micenas no rendían culto a los dioses que presenta Homero: «Las excavaciones de Micenas dejaron al descubierto muchos objetos religiosos (...) pero no hay nada (...) que indique que los griegos de los tiempos de Troya adoraban a los dioses griegos que conocemos» (p. 357) ${ }^{27}$. La autora sólo nos trasmite una religiosidad un tanto salvaje, en la que no faltan los sacrificios humanos, $y$, desde lue-

${ }^{24}$ Frente a lo que la tradición clásica nos dice acerca de la maternidad de Casandra de dos hijos gemelos habidos de Agamenón (Telédamo y Pélope), la novela de Bailey la hace madre de un hijo del héroe (por nombre Diomedes).

25. Ni siquiera se documenta la mención de teónimos griegos, salvo en un par de ocasiones esporádicas, sin explicación ninguna: «Era Dioniso cuando hace el amor con la sacerdotisa para que traiga el sol y vuelva a calentar la tierra en el festival del solsticio» (p. 26), «...se sobrepuso al sonido del tambor mientras recitaba su maldición en nombre de Artemis y Clitemnestra» (p. 255).

${ }^{26}$ La autora no parece considerar que Hécate no se documenta en los poemas homéricos y es ajena a la tradición de la leyenda de Troya. Además la figura de Hécate como diosa de la magia y los hechizos no aparece en los textos más antiguos. Las atribuciones que la diosa tiene en la novela y que Bailey toma de algunas divinidades orientales, parecen ser innovación de la autora.

${ }^{27}$ Esto, desde luego, supone obviar la cantidad de teónimos documentados en las tablillas del Lineal B, coincidentes con los de los dioses griegos del primer milenio (Zeus, Posidón, Dioniso...), de los que, si bien no se puede asegurar que sus atribuciones coincidieran con las de los dioses homéricos del mismo nombre, no por ello dejan de suponer algo mucho más importante que una mera coincidencia. 
go, no hay lugar para dioses tan importantes para la constitución del mito de Casandra como Apolo o Atenea.

e) EI don de profecía: Lógicamente, al no aparecer Apolo en la narración, el don de profecía que caracteriza al personaje se reduce a unas manifestaciones «paranormales» de la protagonista y de su hermano Héleno ${ }^{28}$, que les permiten ver imágenes de lo que va a suceder en el futuro. No se trata, como en la Casandra de Wolf de ataques epilépticos ${ }^{29}$ o de casos especiales de intuición, sino de auténticas visiones que, sin embargo, en la novela no se atribuyen a la intervención de ninguna divinidad concreta: «Cuando Héleno y yo descubrimos que habíamos visto las mismas cosas, mi hermano me dijo que siempre había creído que se trataba de fantasmas; y esperaba que sólo fuera eso porque si era una visión de futuro, era espantosa. Empezábamos a comprender el don que teníamos o habíamos heredado» (p. 17). El descreímiento de sus conciudadanos no se atribuye, consecuentemente a castigo de dios alguno, sino al propio deseo de los troyanos de no aceptar los males que les acechaban: “¿Qué has visto, Casandra? (...) Nada. (...) Dímelo. Pero ¿cómo podía hacerlo? De todas formas no me habría creído» (p. 61).

f) La locura: La asociación entre posesión mántica y locura es un elemento que, como vimos, llega desde Esquilo a Christa Wolf y aparece también de forma constante en Bailey. Los arrebatos visionarios de Casandra y Héleno son interpretados por los demás como un caso de locura; así lo habría entendido Hécuba: «Sabía ( $s c$. Hécuba) que el resultado sería la locura o la profecía (no hay mucha diferencia entre las dos cosas) y escogió la mejor niñera...» (p. 19), y así lo dice explícitamente la nodriza de los gemelos: «(...) habría preferido dos monos o dos cachorros de tigre de Numidia antes que dos niños locos de ojos vueltos, sacudiéndose y sobresaltándose, vociferando desde el momento en que pudisteis hablar, diciéndome cosas que nunca quise oír...» (p. 46).

g) El sufrimiento femenino: Frente al énfasis que Wolf en el tema del sufrimiento femenino, hasta hacer, como Eurípides, a las mujeres las verdaderas víctimas de la guerra, Bailey narra los horrores del asedio y posterior saqueo de Troya sin hacer distinción entre hombres y mujeres. Es más, podemos decir que los personajes femeninos apenas están dibujados y así pasan por el

${ }^{28}$ Por el contrario, Héleno, según la tradición de los textos clásicos, no profetizaba por posesión como Casandra, sino por la interpretación de las vísceras de las aves. También en la novela de Christa Wolf se presenta a Héleno como arúspice.

${ }^{24}$ Así lo interpreta García Gual, C. (op. cit.) p. 1124. 
texto, como sombras, Creusa, Políxena o la propia Hécuba, cuyos caracteres apenas están dibujados. La excepción sería la protagonista, una Casandra irreconocible a partir de los textos clásicos, y su interlocutora Helena, prototípica en sus veleidades, pero con una dosis de crueldad añadida. De la caracterización de los varones podemos destacar la crueldad de Agamenón, la novedad de la traición de Eneas y el carácter más benévolo de Aquiles.

Como decíamos al comienzo, los viejos mitos nos siguen hablando, como lo hicieran en la antigüedad clásica y así, la figura de Casandra, que sirvió a Esquilo para expresar sus más importantes ideas respecto a la culpa y al sufrimiento y a Eurípides para denunciar los horrores de la guerra, ha servido durante el siglo XX, tanto para denunciar la hipocresía religiosa de la sociedad española de los comienzos de la centuria en la obra de Galdós ${ }^{30}$, como la situación de la mujer y de la sociedad de bloques militarizados en la Alemania previa a la unificación, así como para, ya en los desengañados años 90 , construir una novela pseudohistórica que en buena parte prescinde de la parte literaria del mito.

${ }^{30}$ Cf. Hualde, P., «Casandra, de Galdós e Ícara, de Sellés: Mito griego y condición femenina en la España de comienzos del s. XX», en Mitos femeninos de la cultura clásica. Creaciones y recreaciones en la historia de la literatura. Oviedo. KRK, 2003 (en prensa). 